\title{
Raising Student Efforts through Voluntary Learning Tasks in Information Literacy Classes as Outcome of Deploying Learning Advisors*
}

\author{
Koji Sakai, Issei Abe, Daisetsu Fujita \\ Kyoto Koka Women's University, Kyoto, Japan
}

\author{
Kenta Naka \\ Work Academy Corporation, Osaka, Japan
}

\begin{abstract}
As a new initiative in school year 2015-2016 for the course ICT Exercise, we implemented the completion of voluntary learning tasks in addition to required homework for students. The voluntary learning tasks were intended to enhance the learning motivation of students with a high level of computer literacy and encourage academic achievement. A learning advisor was assigned to provide support during specific periods outside of class and prepare reports on support given to the students' instructors. For submitting voluntary learning tasks, students could earn a maximum of 10 additional points to their overall results. Consequently, the submission rate for the voluntary learning tasks was $16 \%$ among a total of 374 undergraduate students. Meanwhile, the number of consultations with the learning advisor increased 2.1 times in 2015 compared with that in 2014, when the voluntary learning task scheme was not yet set. This result indicates that setting higher goals and providing a support system for students promote their learning behavior. The student group that completed the voluntary learning tasks showed a higher learning outcome compared with the student group that did not submit them. Learning outcomes were measured by year-end test and Rasti scores, which help assess capability for the effective use of information technology. We discuss the development of learning environment types to promote students' motivation to learn voluntarily.
\end{abstract}

Keywords: information literacy, voluntary learning tasks, learning advisor, learning outcomes, active learner

\section{Introduction}

Many Japanese universities offer a course on information and communications technology (ICT) for all first-year students. The course contains modules on the use of Microsoft Office, e-mail, and web search engines for students to master the campus information system. Information education, which would deepen the study of any discipline at the university, is also essential for students' professional endeavors after graduation.

The required course ICT Exercise has been offered to all first-year students at Kyoto Koka Women's University. The purpose of the courses is to help students acquire the ability to use information applications and computer systems effectively, such as in gathering, analyzing, editing, and publicizing information properly

\footnotetext{
*Acknowledgments: We appreciate the contribution of Work Academy Co., Ltd. They have provided information on lesson management, learned behavior, other detailed information, and data on the learning outcomes of students. We would like to thank Editage (www.editage.jp) for English language editing.

Koji Sakai, Faculty of Career Development, Kyoto Koka Women's University.

Issei Abe, Faculty of Career Development, Kyoto Koka Women's University.

Daisetsu Fujita, Faculty of Career Development, Kyoto Koka Women's University.

Kenta Naka, Work Academy Corporation.
} 
(Sakai \& Abe, 2012). ICT Exercise I, a course offered in the first half of the school year, helps students acquire computer skills in the use of Microsoft Office, computers, and the internet. ICT Exercise II, offered in the latter half of the school year, hones students' skills learned in ICT Exercise I. Thus, non-freshman students are expected to possess the requisite skills in information application in their respective academic pursuits in their specialized fields. In a number of departments, students can seek advanced instruction in specialized information applications and computer systems in their subsequent years in college. Ida (2014) argued the importance of information literacy for knowledge construction in higher education.

Although many Japanese high schools provide ICT-related education, in which students would master information ethics and skills, such as in the use of Word, Excel, and HTML, many high school graduates would not master the skills in information applications at the necessary level as first-year college students. Instantly, Mizuno and Yasumatsu (2014) researched that 16\% of first-year students had no lessons on computer literacy in their high school. Therefore, ICT Exercise would need to be offered as a mandatory course at our university to benefit those students with low levels of ICT knowledge.

To ensure that such students with low skill levels can understand the content of the course, the following three systems are applied in our university. These systems are considered to yield positive educational effects (Abe \& Sakai, 2015). First, the main lecture instructs students in a large class, and sub-lecturer responds to questions from students in a smaller class. Second, by arranging two or more classes in a particular day and the time of lessons, we can organize two levels of classes: the standard and the basic. The textbook is the same in the two classes, but the course content is slightly changed according to the level of the class. These two systems improve lesson instruction, as illustrated in Figure 1. Third, if students fail to grasp the course content and homework in class, they can consult with their learning advisor outside of class time. This system improves learning support outside of the class, as illustrated in Figure 1.

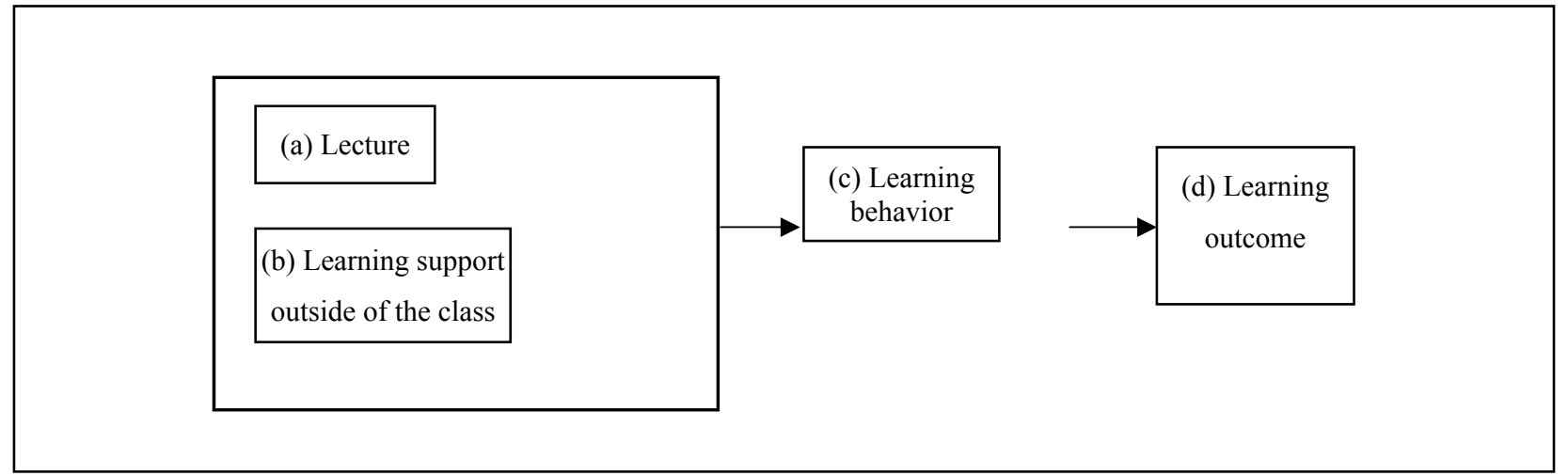

Figure 1. Relationship between promotion of learning behavior and improvement of learning outcomes by the construction of an encouraging learning environment.

Meanwhile, a number of first-year students already master computer skills upon university enrollment. Our aim is for students with a high level of computer literacy to improve their learning outcomes. This gap among students is a problem of the ICT Exercise course in 2015 in light of the results of 2014. Thus, in the first half of school year 2015-2016, we implemented a system that enables students to enhance their learning motivation and academic achievements with respect to higher computer skills. Concretely, we imposed the completion of voluntary learning tasks in addition to the required homework. Students submitted the voluntary learning task to the resident learning advisor, who is responsible for providing learning support to students. 
In this work, we determine whether both students' learning behavior and outcomes are improved by the imposed voluntary learning tasks in the ICT Exercise I course in school year 2015-2016. We compare the data in 2015 to those in 2014, when no voluntary learning tasks were assigned in the same course. Concretely, we verify the following two points: (1) whether the rate of a visit to the learning advisor would increase the submission rate of voluntary learning tasks (i.e., in reference to (c) learned behavior in Figure 1); and (2) whether the learning outcomes, such as year-end test scores, are different between students who complete voluntary learning tasks and those who do not. We then consider further improvements to increase the submission rate of voluntary learning tasks, such as through implementing a learning support environment.

\section{Model of Causal Relationship Between Learning Environment and Learning Outcome}

An Acceleration Program for University Education Rebuilding (AP) from 2014 to 2019 year was adopted at our university. As an AP project, we plan to promote a learning environment for supporting active learner students. Learning environment construction would certainly improve students' learning behavior, and consequently, their learning outcomes (Sakai, Abe, \& Inui, 2014; Sakai, Fujita, Ozawa, Inui, Abe, \& Yamashita, 2016). The learning environment has two components: the lecture and learning support outside of class. Figure 1 shows the causal relationship among the learning environment, learning behavior, and learning outcomes. The learning environment is the cause, whereas learning behavior and learning outcomes are the results. To improve learning outcomes, the learning behavior of students must be promoted by building an encouraging learning environment. To verify this point, the present research collected quantitative data and analyzed whether the construction of the learning environment would lead to the promotion of positive learning behaviors and improvement of learning outcomes.

\section{Materials and Method for the Management System of ICT Exercise}

\section{Management of Human Resources}

From 2013, under the direction of university full-time faculty members, dispatch instructors employed by Work Academy Co., Ltd. are responsible for the ICT Exercise. Information on the class syllabus and operating structure has been reported in Abe and Sakai (2015). In this work, we describe only the management system of the course.

Figure 2 shows a management system diagram of ICT Exercise. A full-time faculty member explains the goals of teaching, evaluation criteria, and the content of ICT Exercise to a person of the in-house coordinator from Work Academy Co., Ltd. A full-time faculty member does not attend the class. One in-house coordinator explains the contents and management of the course to the dispatch lecturers who are responsible for each class. One main lecturer and one sub-lecturer are responsible for each class. The main lecturer handles the class, such as instruction of the exercises, controlling the degree of difficulty, and speed for the entire class. The sub-lecturer follows up on students who could not cope with the progress of the entire class and addresses their questions on auxiliary personal computer operations.

A learning advisor, who is also a sub-lecturer, must be up to speed on the contents of the course and learning progress of the students. The progress of the courses and students in each class is shared among the in-house coordinator and all dispatch instructors through regular meetings or e-mail dispatches. At the end of the semester, the in-house coordinator should discuss and determine the performance evaluation in association with all dispatch instructors. He/she should report the performance evaluation of all classes to a full-time 
faculty member, and the two will deliberate and decide on them. Further, the in-house coordinator summarizes the students' results, such as attendance, homework, voluntary challenge tasks, and year-end test outcomes. $\mathrm{He} / \mathrm{she}$ should submit the report to the full-time faculty member, and the two of them should discuss the improvement of ICT Exercise for the next semester or school year. The faculty member will publicize his/her report on the coordinator's report in conferences on campus.

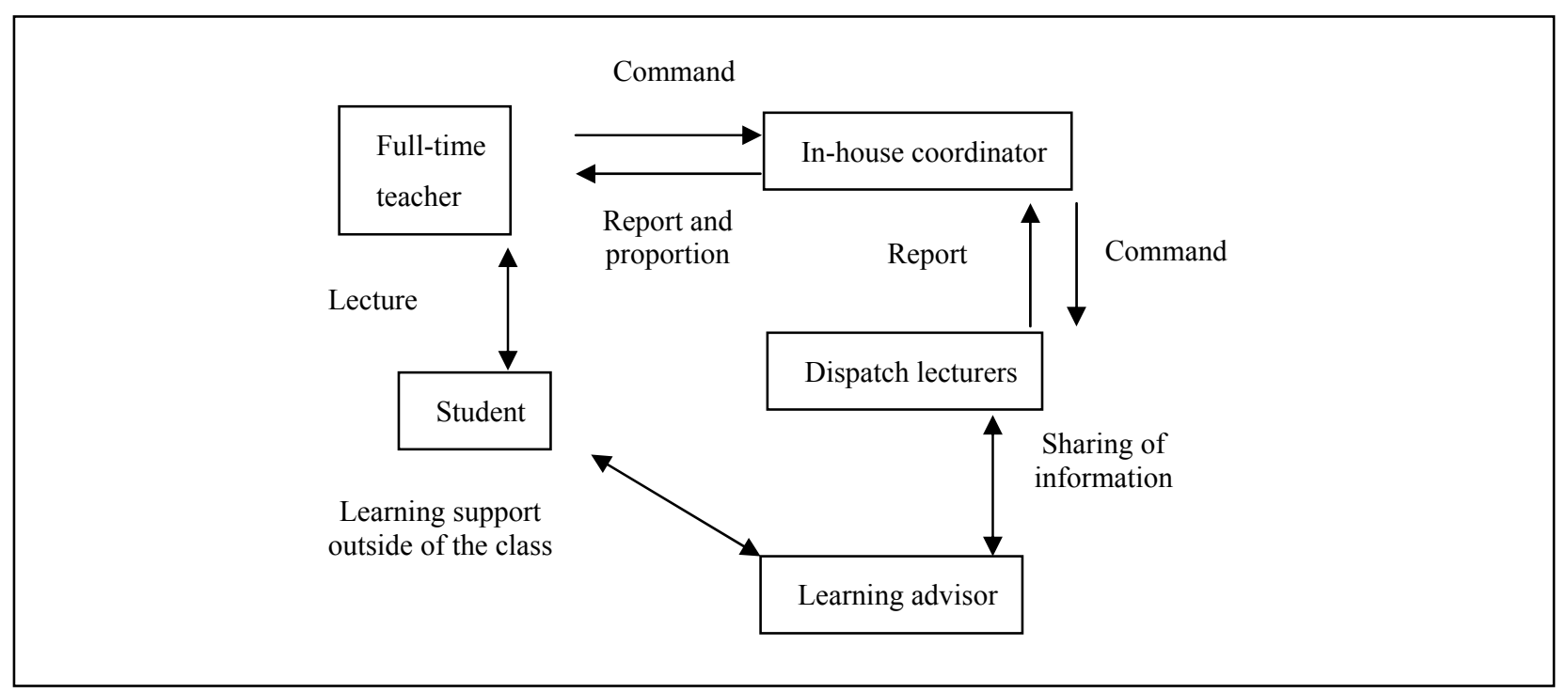

Figure 2. Course management for ICT Exercise.

\section{Arrangement of the Learning Advisor}

Table 1 shows the availability schedule of the learning advisor. All ICT Exercise I classes were placed on Tuesdays or Wednesdays; thus, the learning advisor was made available on these days. The learning advisor was available for nine hours per week in 2015.

Table 1

Schedule of Availability of the Learning Advisor in School Year 2015-2016

\begin{tabular}{lll}
\hline Day & Time & Hours per week \\
\hline Monday & $10: 20-14: 40$ & 3.5 \\
Tuesday & $8: 50-10: 20$ & 1.5 \\
Wednesday & $11: 50-16: 30$ & 4 \\
\hline
\end{tabular}

Figure 3 is an image of the consultation corner where a learning advisor meets students. The learning advisor generally occupies the left side of the desk in Figure 3. When students have questions, they may use any of the laptops at the right side of the image in Figure 3, with assistance by the learning advisor. All students can freely utilize these computers when a learning advisor is not in residence. For the purpose of ease of access, we placed a permanent consultation corner in the lobby of the fifth floor, where dispatch instructors handle ICT Exercise classes.

\section{Differences in Course Management in 2014 and 2015}

Table 2 illustrates the differences in class management between 2014 and 2015. Apart from the initiative of setting voluntary learning tasks, the two years have no significant differences in terms of course operation. The assignment of dispatch instructors and a learning advisor (see Figure 2) has been consistent. The 
consultation corner where the learning advisor meets students (in Figure 3) is in the same place in both years. By setting voluntary learning tasks in 2015, we may verify learning behavior changes, such as the number of visits to the learning advisor, from 2014.

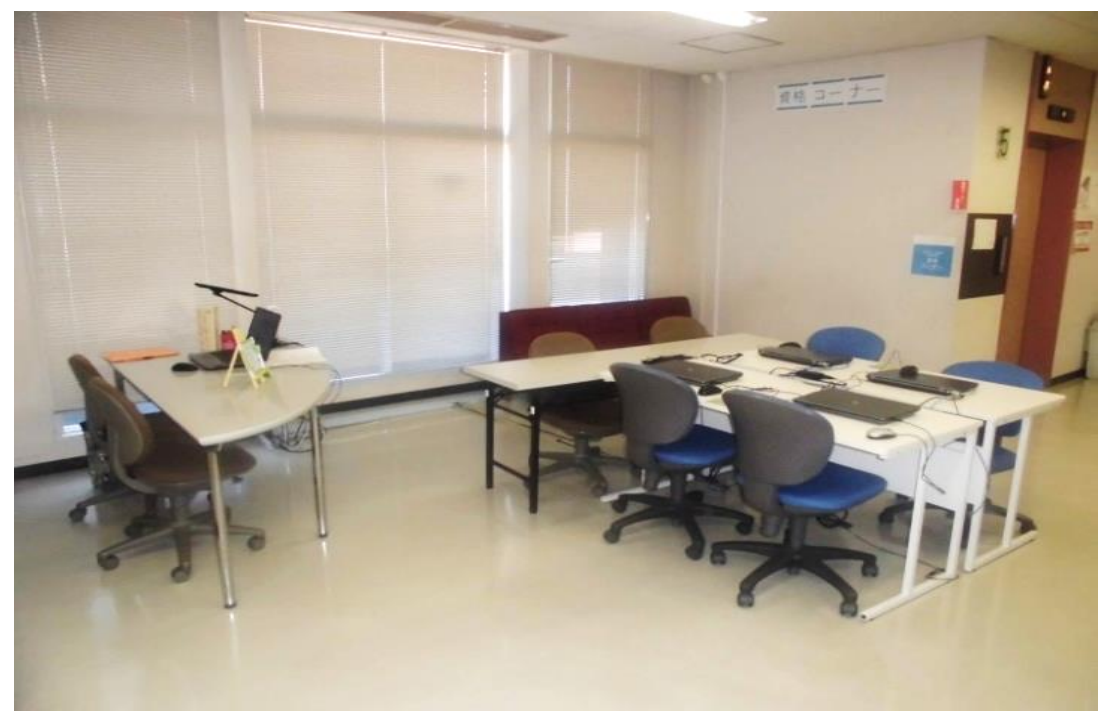

Figure 3. The consultation corner where a learning advisor holds office.

Table 2

Differences in ICT Exercise Between 2014 and 2015

\begin{tabular}{lcc}
\hline & 2015 & 2014 \\
\hline Number of classes & 14 & 12 \\
Number of departments & 6 & 5 \\
Number of students & 374 & 424 \\
Available hours of the learning advisor per week & 9 & 10.3 \\
Voluntary learning tasks & Implemented & Not implemented \\
\hline
\end{tabular}

\section{Contents of Voluntary Learning Tasks}

Table 3

Summary of the Required Homework at Each Lecture

\begin{tabular}{ll}
\hline No. & Contents of the required homework \\
\hline 5 & $\begin{array}{l}\text { Making of guidance handbill (Word) } \\
6\end{array}$ \\
$\begin{array}{l}\text { Typing record tabulation (Word) } \\
\text { Word completion test by e-learning task }\end{array}$ \\
$\begin{array}{l}\text { Tabulation by Excel } \\
\text { Security and information morals completion test by e-learning task }\end{array}$ \\
$\begin{array}{l}\text { Tabulation using a calculation formula (Excel) } \\
10\end{array} \quad \begin{array}{l}\text { Task at the dispatch lecturer's discretion (Excel) } \\
\text { Excel completion test by e-learning task }\end{array}$ \\
$\begin{array}{l}\text { Rasti test on online information application } \\
13\end{array}$ & $\begin{array}{l}\text { Making of a self-introduction slide presentation (PowerPoint) } \\
\text { Typing record tabulation (combination of Word and Excel) }\end{array}$ \\
\hline
\end{tabular}

Table 3 shows an outline of the required homework. Homework was assigned a total of eight times out of fifteen times lectures held in the first half of the school year. Homework constituted $25 \%$ of the overall 
evaluation in ICT Exercise. Dispatch instructors provided ethical approval and informed consent information for students to choose and complete voluntary learning tasks from the e-learning platform NESS, and then submitted these to the learning advisor. NESS is an online system that contains teaching materials on information education (e.g., use of Word, Excel, PowerPoint); it is a teaching aid that complements the assigned textbooks. The date, time, and frequency of submission of voluntary learning tasks were not determined particularly. The learning advisor should check the submitted voluntary learning tasks, and then respond to students when they have questions.

\section{Methods of Evaluation for Voluntary Learning Tasks}

Proficiency in the voluntary learning tasks was not reflected in the evaluation. Submission of voluntary learning tasks could earn students up to 10 points added to the results of the previous year. This was based on the findings of Takami, Sugiura, and Simai (2012) that most of students did not tackle voluntary tasks though they could easily access them in the internet, unless they could have some incent. The students were notified that the submission of voluntary learning tasks would be reflected in the results of their evaluation but not of the specific point earned based on performance of the voluntary learning tasks.

There are two types of voluntary learning tasks in NESS, and point allocations were added in the following manner. First, for Microsoft Office exercises (Word/Excel/PowerPoint), one point was added when one task is submitted. Second, for character input tasks, the following points were added related to the number of tasks submitted: one point per four submissions, 2 points for 5 to 9 submissions, 3 points for 10 to 14 submissions, and 4 points for 15 submissions.

\section{Results}

\section{Submission Rate for Voluntary Learning Tasks}

Table 4 shows the submission rate of the voluntary learning tasks in the first half of 2015, compared between beginner and intermediate classes. A total of 60 students, $16 \%$ of all 374 students, submitted more than one voluntary learning task. The submission rate was $19.3 \%$ in the intermediate class, which was better than the $13.0 \%$ of the beginner class. Thus, students in the intermediate class worked more actively on the voluntary learning tasks. Students in the beginner class tended to remember the anxiety on test scores, etc. to get the additional points. Meanwhile, students in the intermediate class worked on the tasks to train for the tests or to enhance their computer skills.

Table 5 provides the frequency distribution for the 60 students that received additional points by submitting voluntary learning tasks. Among the 60 students, 19 earned one point by submitting only one task. More than half ( 33 students, 55\%) of the same 60 students earned only 1 or 2 points. Meanwhile, only four students earned the maximum of 10 points.

\section{Frequency of Visit to the Learning Advisor}

Students must visit the learning advisor to submit the voluntary learning tasks. Table 6 lists the annual change in the number of visits to the learning advisor. There were more visits from May to July, when the homework and voluntary learning tasks were given to students. This trend is similar to the findings of Seki (2011) that some students visited an academic advisor on April at the beginning of course, but inversely many visited him from May to July to help their lessons or homework. The number of visits in 2015 increased 2.1 times compared with that in 2014. 
Table 4

Submission Rate of the Voluntary Learning Tasks

\begin{tabular}{llll}
\hline & Basic class & Middle class & Total \\
\hline Number of submissions & 24 & 36 & 60 \\
Rate of submission & $13.0 \%$ & $19.3 \%$ & $16.0 \%$ \\
\hline
\end{tabular}

Table 5

Distribution Frequency of Each Point Given for the Submission of Voluntary Learning Tasks

\begin{tabular}{lc}
\hline Additional points & Number of students \\
\hline 10 & 4 \\
9 & 1 \\
8 & 1 \\
7 & 2 \\
6 & 2 \\
5 & 6 \\
4 & 6 \\
3 & 5 \\
2 & 14 \\
1 & 19 \\
\hline
\end{tabular}

Table 6

Change in the Number of Student Visits to the Learning Advisor in 2014 and 2015

\begin{tabular}{llllll}
\hline & April & May & June & July & Total \\
\hline 2014 & 25 & 40 & 40 & 37 & 142 \\
2015 & 33 & 88 & 81 & 91 & 293 \\
\hline
\end{tabular}

Table 7

Details of the Contents of Consultations with the Learning Advisor in 2015

\begin{tabular}{lccccc}
\hline Contents of consultations & April & May & June & July & Total \\
\hline ID for login & 1 & 4 & 0 & 0 & 5 \\
Contents of lecture $^{*}$ & $8(1)$ & $61(29)$ & $74(31)$ & $91(20)$ & $234(81)$ \\
Purchase of PC & 11 & 1 & 1 & 0 & 13 \\
Others & 13 & 22 & 6 & 0 & 41 \\
Total & 33 & 88 & 81 & 91 & 293 \\
Days of advisor availability & 10 & 9 & 14 & 10 & 43 \\
Consultations per day & 3.3 & 9.8 & 5.8 & 9.1 & 6.8 \\
\hline
\end{tabular}

Note. ${ }^{*}$ Data on 2014 year in the parentheses.

Table 7 shows the consultation content and number of visits to the learning advisor from April to July. The column for "homework and voluntary learning tasks" indicates the visits for consultation on or submission of homework and voluntary learning tasks. In 2015, there were 234 cases, which were 2.9 times more than the 81 cases in 2014, although the number of students taking ICT Exercise was greater in 2014 than in 2015 (see Table 2). These 234 consultations from April to July comprised $79.9 \%$ of the total 293 consultations for the entire school year. Many students were particularly seeking support on Excel operation. Homework on Excel exercises was often assigned in June. As such, the number of consultations was supposed to peak in June. However, in 2015, as the voluntary learning tasks were assigned, the number of consultations increased 
dramatically compared with the case in 2014. Many students probably wanted to earn credits toward a high score on their year-end test. The implementation of the voluntary learning tasks would certainly be a major factor for the increase in the number of consultations to the learning advisor in 2015.

\section{Student Awareness of the Learning Advisor}

Table 8 shows the rate of awareness and uses experience of students as regards the learning advisor. As the scheme was repeatedly announced in each class, nearly all of the students (96\%) were aware of the available learning support offered by the learning advisor. However, students who never utilized such support constituted a high percentage (65\%). Table 9 shows the reasons that students do not visit the learning advisor. The percentage of students who did not require consultation was the highest at $38 \%$. The reason may be that the sub-lecturer for each class already provided support during a lecture. Meanwhile, $28 \%$ of students reported that they could not arrange the time to meet the advisor, and therefore, could not consult with the learning advisor.

Table 8

Awareness and Use Experience of Students as Regards the Learning Advisor

\begin{tabular}{ll}
\hline Awareness and use experience & Percentage \\
\hline Aware and use experience & $31 \%$ \\
Aware but no use experience & $65 \%$ \\
Unaware & $2 \%$ \\
\hline
\end{tabular}

Table 9

Reasons Students Do Not Visit the Learning Advisor

\begin{tabular}{ll}
\hline Reason for not visiting the learning advisor & Percentage \\
\hline I understood the lecture and so didn't need consultation & $38 \%$ \\
I could not find the time & $28 \%$ \\
Others & $17 \%$ \\
Unanswered & $17 \%$ \\
\hline
\end{tabular}

\section{Learning Outcome Improvement by Efforts toward Voluntary Learning Work}

In this section, we verify the effects of the submission of voluntary learning tasks on learning outcomes. For this, we compare the differences in learning outcomes between the group that submitted the tasks and the group that did not. Table 10 shows a comparison of the seven indicators of learning outcomes for the two groups. The difference in points between the two groups is clear in all seven of the indicators; the submission group had a higher average score compared with the non-submission group. In particular, the difference was great in the Rasti test, which is largely recognized in Japan as an assessment for information literacy.

The higher points of the submission group may be attributed to the group's already higher learning motivation and computer literacy before attending the ICT Exercise course. In other words, there may be a causal relationship in which “(d) learning outcome” would affect the "(c) learning behavior" in Figure 1. It would be likely difficult to verify with quantitative data that self-learning behavior would clearly cause improvement of learning outcomes. To determine clearly the direction of a causal relationship, qualitative research and analysis, including interviews with students, would be necessary. However, the present data should clarify that the submission group had high learning outcomes, as shown in Table 10. It is important to establish the appropriate learning support system to ensure that higher performing student groups can further enhance their learning behaviors and outcomes. 
Table 10

Comparison of the Learning Outcomes (Average Scores) Between the Voluntary Learning Task Submission and Non-submission Groups

\begin{tabular}{lcc}
\hline & $\begin{array}{l}\text { Submission group } \\
(60 \text { students })\end{array}$ & $\begin{array}{l}\text { Non-submission group } \\
(314 \text { students })\end{array}$ \\
\hline Total-semester & 88.3 & 79.3 \\
Rasti test & 474.0 & 442.2 \\
Homework & 22.0 & 20.0 \\
Test for Word & 8.3 & 8.1 \\
Test for Excel & 8.5 & 7.9 \\
Final-semester test & 12.3 & 11.6 \\
E-learning for Word/Excel & 14.4 & 13.2 \\
\hline
\end{tabular}

\section{Discussion}

The high learning outcomes of the submission group indicate the importance of encouraging students to submit voluntary learning tasks. In this section, we discuss learning environment types and support that help further improve the submission rate of voluntary learning tasks. Subsequently, we discuss the training system for active learners through the efforts toward completing voluntary learning tasks.

\section{Improvement in the Submission Rate of Self-learning Tasks}

The submission rate of voluntary learning tasks was $16.0 \%$ (see Table 4). Although the number of students' visits to the learning advisor increased from that in 2014 (see Table 6), the submission rate of $16.0 \%$ is not very high. To improve the submission rate of voluntary learning tasks to $25 \%$, the following technical methods need improvement.

(a) Submission method: In 2015, students need to submit voluntary learning tasks to the learning advisor in person. Consequently, as shown in Table 9, 28\% of students could not do so owing to time constraints. In future, we shall improve the method of submission by considering how the learning advisor can also accept submissions via e-mail or a learning management system (LMS). However, we should verify whether the feedback on voluntary learning tasks from the learning advisor by e-mail would affect learning outcomes, compared with the face-to-face consultation with the learning advisor.

(b) Scoring method: In 2015, submission frequency of voluntary learning tasks, not actual performance, was reflected in the scoring. Learning behavior would be enhanced if both performance and submission would be evaluated and scored; for example, the scoring system can be changed to follow three stages such as high, middle, and low.

(c) Self-confirmation of the submission status: The learning advisor reflected the filing of the submission status for each student in the performance evaluation. However, students could not record the submission status, as there was no LMS or similar mechanism in place; the students themselves were required to record their submission. If the students could check the learning efforts and grasp the submission scheme of their voluntary learning tasks in LMS, they may be more likely to submit tasks.

The original purpose for assigning a learning advisor was to provide support students with a low level of understanding of the course content; supporting students in undertaking additional work through the voluntary learning tasks was second priority. The number of "contents of the lecture" for 2015 in Table 7 contains the cases of consultations on the homework and voluntary learning tasks. Meanwhile, the number of "contents of the 
lecture" for 2014, when students were not given voluntary learning tasks, does not contain the cases of consultations on the voluntary learning tasks. Increasing the number of consultations for homework would enhance the learning support for students with low proficiency. This support could also lead to increased confidence in mastering homework, and consequently encourage students to attempt and complete voluntary learning tasks.

\section{Development of Active Learners Through Self-learning Task Efforts}

The voluntary learning task scheme was set for the main purpose of encouraging students with a high level of ICT literacy to obtain higher learning outcomes. However, the effect of voluntary learning tasks was not limited to learning outcomes. Even if students are initially motivated by the point addition from task performance, the habit of continuing to tackle the voluntary learning tasks might cultivate endogenous, autonomous learning behavior to aim at higher goals.

In AP projects at our university, we should implement environmental construction that can promote students' learning efforts, including the voluntary learning tasks. Sakai et al. (2014) set up the following four active learner (AL) levels as attitudes of proactive learning conducive to training active learners stepwise.

At AL level 0: Students do not complete homework at all.

At AL level 1: Students are not eager to tackle homework and have a low submission rate.

At AL level 2: Students tackle homework with a higher enthusiasm and with the cooperation of others, such as the learning advisor.

At AL level 3: Students can tackle homework alone proactively.

At AL level 4: Students can support other students in their homework.

The goal of our university is to foster students at the AL level 3. Both the arrangement of the learning advisor and voluntary learning tasks comprise the learning support system aimed at the development of $\mathrm{AL}$ levels. At AL Level 2, students themselves could not complete fully the homework or voluntary learning task, but could solve problems properly through consultation with a learning advisor. At AL Level 3, students themselves can solve learning tasks. By imposing learning hurdles, such as voluntary learning tasks, first-year students can form the habit of challenging themselves to seek higher goals. Through the voluntary learning tasks in this study, students could master learning management and apply it effectively in other courses.

We plan to consider improvements in the environment of learning support and method of consultation with learning advisors to encourage students toward becoming active learners. Based on the quantitative analysis in this study, we will conduct interviews with students in the submission group as regards their efforts toward voluntary learning tasks. Such interviews may confirm that tackling voluntary learning tasks would improve learning attitudes and behaviors, and consequently, learning outcomes. Concretely, we would select a few students with a high submission rate from the 60 students in the submission group. We would ask them the following questions: (a) Their reason for continuing to submit voluntary learning tasks, (b) whether or not the submission of voluntary learning tasks affected the improvement of their learning outcomes, (c) the effect of consultations with the learning advisor on their level of motivation, and (d) the adjustments they made to their schedule to accommodate visits to the learning advisor. Subsequently, we could improve the teaching and learning support system in ICT Exercise. This system would be necessary for elevating the AL levels of our students.

\section{References}

Abe, I., \& Sakai, K. 2015. Issues and improvement of common information literacy education. Japan Society for Information and Systems in Education Research Report, 29(5), 123-126. 
Ida, H. 2014. Designing the "knowledge creative" information literacy education. The Journal of Information Science and Technology Association, 64(1), 8-14.

Mizuno, Y., \& Yasumatsu, N. 2014. A study on development of educational models of information processing in first year experience. Bulletin of Toyo Gakuen University, 22, 179-192.

Sakai, K., \& Abe, I. 2012. A Method for mastering the use of information application and information literacy. Japan Society for Information and Systems in Education Research Report, 26(6), 61-68.

Sakai, K., Abe, I., \& Inui, A. 2014. Creating organized support systems for improving students' learning and acquiring performance. Research report of Japan Society for Educational Technology, 14(5), 275-282.

Sakai, K., Fujita, D., Ozawa, C., Inui, A., Abe, I., \& Yamashita, H. 2016. Analysis of questionnaire survey aimed at development of "active learners level" assessment. Research Report of Japan Society for Educational Technology, 16(1), 5-12.

Seki, A. 2011. Reflections on the activities of study advisors in tertiary education in Japan: A case study of English study advisors' practice in Tokyo Keizai University. The Journal of Humanities and Natural Sciences, 130, 95-106.

Takami, S., Sugiura, M., \& Simai, S. 2012. A situation of practical use of learning resources showed on web by college students. Journal of Japanese Red Cross Toyota College of Nursing, 7(1), 167-171. 